Feny Aldiana, Asep M. Ramdan, dan Acep Samsudin. Kekuatan Kepercayaan Terhadap Minat Beli ... 220

\title{
KEKUATAN KEPERCAYAAN TERHADAP MINAT BELI PENGUNJUNG WEBSITE
}

\author{
Feny Aldiana ${ }^{1}$ \\ Asep M. Ramdan ${ }^{2}$ \\ Acep Samsudin ${ }^{3}$ \\ ${ }^{1}$ Mahasiswa program studi Administrasi Bisnis Universitas Muhammadiyah Sukabumi \\ 2, ${ }^{3}$ Pengajar program studi Administrasi Bisnis Universitas Muhammadiyah Sukabumi \\ Email : fenyaldiana03@gmail.com¹,amr37ramdan@gmail.com²,Chevysys_77@yahoo.com³
}

\begin{abstract}
Strength of Trust in the Interest of Buying Website Visitors. The purpose of this study is to measure the effect of trust in buying interest in website visitors. The subject in this study is the buying interest of website visitors and the object is the trust of website visitors. The method used in this study is to use the type of sampling included in the type of saturated sample by doing a questionnaire of 130 respondents from website visitors. The type of data collected is quantitative data using the questionnaire method and analyzed using simple linear regression analysis including the coefficient of determination test, and partial test ( $t$ test). The results of the test coefficient of determination seen from the value (Adjusted $R$ ) of 0.613 can be interpreted that the influence of trust in buying interest is $61.3 \%$, the remaining $38.7 \%$ is influenced by other factors not explained in this study. Based on a simple correlation coefficient test seen from the $R$ value of 0.784 shows that there is a strong relationship between trust and buying interest. Based on the t test, trust $(X)$ has a positive and significant effect on buying interest $(Y)$ on website visitors, the regression coefficient obtained is positive 0.711 and t count is 15.070 with a significant of 0.000
\end{abstract}

Keywords: Trust, purchase intentions

Abstrak: Kekuatan Kepercayaan Terhadap Minat Beli Pengunjung Website. Tujuan penelitian ini untuk mengukur pengaruh kepercayaan terhadap minat beli pada pengunjung website. Subjek dalam penelitian ini adalah minat beli pengunjung website dan objeknya adalah kepercayaan pengunjung website. Metode yang digunakan dalam penelitian ini adalah menggunakan jenis sampling termasuk kedalam jenis sampel jenuh dengan melakukan kuesioner sebanyak 130 responden dari pengunjung website. Jenis data yang dikumpulkan adalah data kwantitatif dengan menggunakan metode kuisioner serta di analisis dengan menggunakan analisis regresi linear sederhana termasuk uji koefisien determinasi, dan uji secara parsial (uji t). Hasil penelitian uji koefisien determinasi dilihat dari nilai (Adjusted R) sebesar 0,613 dapat diartikan bahwa pengaruh kepercayaan terhadap minat beli adalah $61,3 \%$ sisanya $38,7 \%$ di pengaruhi oleh faktor lainnya yang tidak di jelaskan dalam penelitian ini. Berdasarkan uji koefisien kolerasi sederhana dilihat dari nilai $\mathrm{R}$ sebesar 0,784 menunjukan bahwa terjadi hubungan kuat antara kepercayaan dan minat beli. Berdasarkan uji t, kepercayaan (X) berpengaruh positif dan signifikan terhadap minat beli (Y) pada pengunjung website diperoleh koefisien regresi yang bernilai positif 0,711 dan thitung sebesar 15.070 dengan signifikan sebesar 0,000 .

Kata Kunci: Kepercayaan, Minat Beli 


\section{PENDAHULUAN}

Penelitian tentang minat beli ini telah dikaji selama 20 tahun terakhir pada bidang industry media website (Erlang prima insani 2013), pada bidang jasa (Ferdinand Augusty 2002), pada bidang produksi (Arief adi satria 2017), pada bidang pemasaran (Ahmad makhin 2016), pada bidang perdagangan (Veronika (2016). Laporan presentasi we are social menunjukan bahwa dalam kurun waktu satu bulan pada tahun 2017, adanya potensi yang tinggi sebesar $41 \%$ masyarakat Indonesia yang membeli barang atau jasa secara online dari total populasi yang mengalami peningkatan sebesar $15 \%$ di bandingkan tahun sebelumnya yang hanya $26 \%$ sehingga dalam pola perubahan prilaku belanja yaitu salah satu yang terlihat saat ini adanya volume transaksi melalui website yang meningkat. Hal ini menunjukan bahwa masyarakat saat ini sudah berpindah dari offline menjadi online atau menjadi pembeli digital, perubaan tersebut tidak dapat di pungkiri bahwa saat ini bisnis tidak bisa jauh atau terlepas dari dunia digital.

Website menjadi media efektif dalam menyampaikan informasi penjualan sehingga dapat memudahkan pengunjung dalam memahami suatu produk yang akan di beli. Tidak hanya memberikan kemudahan bagi pembeli, website juga memiliki kemudahan kepada para dropshiper dalam mendapatkan kemudahan dalam mempromosikan produknya karena meraka cukup membagikan link website di media sosial sehingga para pembeli dengan mudah berbelanja melalui website berbentuk seperti e-commece. Sehingga dalam perkembangannya, belanja online melalui website dapat menumbuhkan minat beli pengunjung dengan kemudahan dan informasi yang lengkap mengenai suatu produk, sehingga menjadi daya tarik pengunjung untuk berbelanja melalui website.

Tidak sebagian orang menganggap pembelian online menjadi pilihan yang efektif untuk membantu persoalan dalam berbelanja, karena sebagian orang menggap dalam sistem yang berbasis online adanya resiko yang kemungkinan akan terjadi seperti resiko penipuan, kekhawatiran yang berkaitan dengan keamanan dalam bertransaksi serta resiko adanya kurangnya kepercayaan terhadap barang yang akan di beli. Menurut (Dazmin Daud dan Padzil Hassan, 2015) dalam transaksi online, tidak adanya interaksi fisik antara pembeli dan penjual, sehingga meningkatkan kemungkinan kesalahan transaksi yang digunakan secara tidak benar.

Kepercayaan sebagai kesediaan untuk bergantung kepada pihak lain yang telah dipercaya. Sehingga dasar terciptanya hubungan jangka panjang terletak pada kepercayaan antara pengunjung dengan produsen melalui hubungan jarak jauh atau secara online melalui website, dalam transaksi secara online pembeli tidak dapat melihat secara langsung barang atau produk yang akan di beli, sehingga hadirya website menjadi salah satu media yang akan digunakan sebagai sumber informasi mengenai barang atau produk oleh pengunjung, karena informasi yang di sampaikan oleh penjual sepenuhnya menjadi salah satu kepercayaan pembeli atau pengunjung terhadap website tersebut. (Ishak dan Luthfi 2011:59) (Veronika 2016)

Masalah yang sering dihadapi pada website salah satunya adalah kurangnya minat dalam membeli pengunjung yaitu minat keinginan pengunjung dalam membeli produk pada website, kurangnya keinginan pengunjung terhadap produk yang di minati pada website ataupun kurangnya pengalaman pengunjung dalam mengetahui produk yang ada di website.

Tema yang diusulkan ialah Analisis kekuatan kepercayaan terhadap minat beli pengunjung website. Tujuan penelitian ini untuk mengukur pengaruh kepercayaan terhadap minat beli pengunjung website.

\section{Tinjauan Pustaka}

\section{Kepercayaan}

Kepercayaan adalah kemauan perusahaan untuk mengandalkan mitra bisnis, karena adanya interaksi anatara penjual dan pembeli secara online. (Kotler dan Keller 2016:231) (Fahreza dan Devilia 2017) Sementara itu kepercayaan merupakan komponen kognitif dari faktor psikologis. 
(Kotler dan Keller 2012:125)

Sedangkan menurut (Christian 2015), menyatakan bahwa ada dua dimensi kepercayaan pengunjung, yaitu: Trusting Belief dan Trusting Intention

1. Trusting Belief adalah persepsi pihak yang percaya (pengunjung) terhadap pihak yang dipercaya perusahaan/website yang mana penjual memiliki karakteristik yang akan menguntungkan pengunjung. (Christian 2015), menyatakan bahwa ada tiga elemen yang membangun Trusting Belief, yaitu benevolence, integrity, competence.

a) Benevolence (niatbaik) berartiseberapa besar seseorang percaya kepada penjual untuk berperilaku baik kepada pengunjung. Benevolence merupakan kesediaan penjual untuk melayani kepentingan (McKnight et al.,2001)

b) Integrity (integritas) adalah seberapa besar keyakinan seseorang terhadap kejujuran penjual untuk menjaga dan memenuhi kesepakatan yang telah dibuat kepada pengunjung. (McKnight et al.,2001)

c) Competence (kompetensi) adalah keyakinan seseorang terhadap kemampuan yang dimiliki penjual untuk membantu pengunjung dalam melakukan sesuatu sesuai dengan yang dibutuhkan pengunjung tersebut. Esensi dari kompetensi adalah seberapa besar keberhasilan penjual untuk menghasilkan hal yang diinginkan oleh pengunjung. Inti dari kompetensi adalah kemampuan penjual untuk memenuhi kebutuhan pengunjung. (McKnight et al.,2001)

2. Trusting Intention adalah suatu hal yang disengaja dimana seseorang siap bergantung pada orang lain dalam suatu situasi, ini terjadi secara pribadi dan mengarah langsung kepada orang lain. Selain itu Christian 2015, menyatakan bahwa ada dua elemen yang membangun Trusting Intention yaitu willingness to depend dan subjective probability of depending.

a) willingness to depend adalah kesediaan pengunjung untuk bergantung kepada penjual berupa penerimaan resiko atau konsekuensi negatif yang mungkin terjadi. (McKnight et al.,2001) b) Subjective probability of depending adalah kesediaan pengunjung secara subjektif berupa pemberian informasi pribadi kepada penjual, melakukan transaksi,serta bersedia untuk mengikuti saran atau permintaan dari penjual. (McKnight et al.,2001)

\section{Minat Beli}

Minat beli pengunjung adalah sebuah perilaku pengunjung dimana pengunjung mempunyai keinginan dalam membeli atau memilih suatu produk, berdasarkan pengalaman dalam memilih, menggunakan dan mengkonsumsi atau bahkan menginginkan suatu produk. (Kotler dan Keller 2014) (Aditya 2015:36). Selain itu niat membeli merupakan, kemampuan untuk merekomendasikan perusahaan dan merek kepada orang lain, dan atribut tertentu atau persepsi manfaat kemungkinan terkait dengan kepuasan pelanggan (Kotler dan keller 2016:155)

Menurut Veronika 2017 mengatakan bahwa indikator dari minat beli, meliputi:

1. Minat transaksional yaitu kecenderungan seseorang untuk membeli produk yang akan dikonsumsinya. (Ferdinand 2002:129)

2. Minat referensial yaitu kecenderungan seseorang untuk mereferensikan produk yang sudah dibelinya, agar juga dibeli oleh orang lain, dengan referensi pengalaman konsumsinya. (Ferdinand 2002:129)

3. Minat preferensial yaitu minat yang menggambarkan perilaku seseorang yang selalu memiliki preferensi utama pada produk yang telah dikonsumsi. Preferensi ini hanya dapat diganti bila terjadi sesuatu dengan produk preferensinya. (Ferdinand 2002:129)

4. Minat eksploratif yaitu prilaku seseorang yang selalu mencari informasi mengenai produk yang diminatinya dan mencari informasi untuk mendukung sifatsifat positif dari produk tersebut. (Ferdinand 2002:129)

Sedangkan hubungan kepercayaan terhadap minat beli menurut Sofia Imari et all,. (2017) menyatakan bahwa," adanya terdapat pengaruh yang positif dan signifikan antara kepercayaan online terhadap niat beli 
Tabel 1

Hasil Uji Regresi Linear Sederhana

Coefficients $^{\mathbf{a}}$

\begin{tabular}{|c|c|c|c|c|c|c|}
\hline \multirow[b]{2}{*}{ Model } & & \multicolumn{2}{|c|}{ Unstandardized Coefficients } & \multirow{2}{*}{ 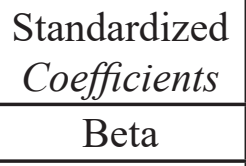 } & & \multirow[b]{2}{*}{ Sig. } \\
\hline & & $\mathrm{B}$ & Std. Error & & & \\
\hline \multirow[t]{2}{*}{1} & (Constant) & .454 & .749 & & .607 & .545 \\
\hline & kepercayaan & .711 & .047 & .784 & 15.070 & .000 \\
\hline
\end{tabular}

a. Dependent Variable: minat beli

Sumber : Data Primer (Kuesioner), 2019

Tabel 2

Hasil Koefisien Determinasi

Model Summary

\begin{tabular}{|l|l|r|r|r|}
\hline Model & $\mathrm{R}$ & R Square & Adjusted R Square & $\begin{array}{c}\text { Std. Error of the } \\
\text { Estimate }\end{array}$ \\
\hline 1 & $.784^{\mathrm{a}}$ & .615 & .613 & 2.072 \\
\hline
\end{tabular}

a. Predictors: (Constant), kepercayaan

Sumber : Data Primer (Kuesioner), 2019

pelanggan secara online" selain itu Riski menggunakan jenis sampling termasuk Rosdiana dan iyus akhmad haris (2018) kedalam jenis sampel jenuh dengan mwngatakan bahwa "terdapat pengaruh positif melakukan kuesioner sebanyak 130 responden variable kepercayaan terhdap minat beli dari pengunjung website. Jenis data yang produk secara online". Hal ini menunjukan dikumpulkan adalah data kwantitatif dengan adanya arah positif atau hubungan searah dari menggunakan metode kuisioner serta di analis minat beli pengunjung.

H1 Pengaruh kepercayaan terhadap minat beli pengunjung website

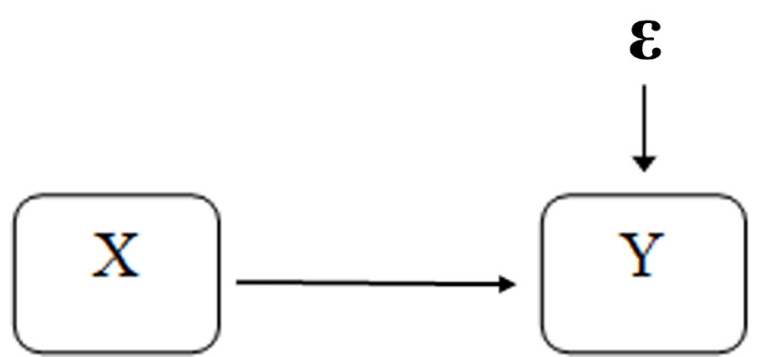

Gambar 1 Paradigma Penelitian

Sumber : data diolah penulis 2019

Keterangan:

Variabel $(\mathrm{X}) \quad=$ Kepercayaan

Variabel $(\mathrm{Y})=$ Minat Beli

$\varepsilon \quad=$ variabel yang tidak diteliti

dalam penelitian dengan menggunakan analisis regresi linear sederhana termasuk uji koefisien determinasi, dan uji secara parsial (uji t).

\section{Hasil Analisis Regresi Linear Sederhana}

Regresi linear sederhana sangat bermanfaat untuk meneliti hubungan fungsional ataupun kausal satu variabel independen dengan satu variabel dependen. Hasil regresi linear sederhana dapat dilihat pada tabel 1.

Dari output uji regresi linear sederhana diatas, maka dapat diperoleh persamaan sebagai berikut:

$$
\mathrm{Y}=0,454+0,711
$$

\section{Koefisien Determinasi ( $R$ )}

Hasil tabel 2 diatas model summary

\section{METODE PENELITIAN}

Penelitian ini dilaksanakan di website dropshipan.co.id yang dinaungi oleh $\mathrm{Cv}$ Ultiface Selamet Nugraha, Metode yang digunakan dalam penelitian ini adalah berdasarkan adjusted $\mathrm{R}$ adalah 0,613; hal ini berarti $61,3 \%$ variasi minat beli dapat dijelaskan oleh variasi dari variabel independen kepercayaan sedangkan sisanya $38,7 \%(100 \%-61,3 \%=38,7 \%)$ dari faktor 
Tabel 3

Hasil Koefisien Korelasi Sederhana

Model Summary

\begin{tabular}{|l|l|r|r|r|}
\hline Model & $\mathrm{R}$ & R Square & Adjusted R Square & $\begin{array}{c}\text { Std. Error of the } \\
\text { Estimate }\end{array}$ \\
\hline 1 & $.784^{\mathrm{a}}$ & .615 & .613 & 2.072 \\
\hline
\end{tabular}

a. Predictors: (Constant), kepercayaan

Sumber : Data Primer (Kuesioner), 2019

Tabel 4

Hasil Uji t

Coefficients $^{\mathrm{a}}$

\begin{tabular}{|c|c|c|c|c|c|c|}
\hline \multirow{2}{*}{\multicolumn{2}{|c|}{ Model }} & \multicolumn{2}{|c|}{ Unstandardized Coefficients } & \multirow{2}{*}{$\begin{array}{c}\begin{array}{c}\text { Standardized } \\
\text { Coefficients }\end{array} \\
\text { Beta } \\
\end{array}$} & \multirow[b]{2}{*}{$\mathrm{t}$} & \multirow[b]{2}{*}{ Sig. } \\
\hline & & $\mathrm{B}$ & Std. Error & & & \\
\hline 1 & (Constant) & .454 & .749 & & .607 & .545 \\
\hline & kepercayaan & .711 & .047 & .784 & 15.070 & .000 \\
\hline
\end{tabular}

a. Dependent Variable: minat beli

Sumber : Data Primer (Kuesioner), 2019

yang tidak diteliti.

\section{Koefisien Kolerasi Sederhana (R)}

Berdasarkan tabel 3 diatas diperoleh angka $\mathrm{R}$ sebesar 0,784 berada pada katagori $0,60-0,799$. Hal ini menunjukan bahwa terjadi hubungan yang kuat antara kepercayaan terhadap minat beli.

\section{Uji Signifikan Secara Parsial (Uji t)}

Berdasarkan tabel 4 diatas, hasil uji hipotesis uji t yang dilakukan dapat dililat bahwa variabel kepercayaan nilai sig. 0,000 $<0,05$; nilai t hitung $15.070>\mathrm{t}$ tabel 1.9789, artinya kepercayaan berpengaruh positif dan signifikan secara parsial terhadap minat beli.

\section{PEMBAHASAN}

\section{Hasil Uji Hipotesis}

H1: Kepercayaan berpengaruh terhadap minat beli pengunjung website

\section{Pengaruh Kepercayaan terhadap Minat Beli (Y)}

(X)

Berdasarkan pada hasil analisis regresi sederhana uji $t$ dengan tingkat signifikan sebesar 0,05 (5\%) menunjukan bahwa variabel kepercayaan $(\mathrm{X})$ berpegaruh terhadap minat beli (Y). Hal ini ditujukan dengan hasil nilai $\operatorname{sig} 0.00<0,05$ nilai $\mathrm{t}_{\text {hitung }} 15.070>\mathrm{t}_{\text {tabel }} 1.9789$.
Nilai Koefisien determinasi (R) diperoleh hasil dari variabel $(\mathrm{X})$ Kepercayaan mempengaruhi sebesar 0,613 (61,3\%) terhadap minat beli (Y), sisanya $38,7 \%$ dari faktor yang tidak dibahas dan di teliti. Semakin tinggi kepercayaan pengunjung terhadap website tersebut, maka semakin tinggi minat untuk membeli produk melalui website. Sehingga dapat diasumsikan bahwa ketika responden mengunjungi website pada dasarnya pengunjung akan melihat produk yang ada di dalam website Oleh karena itu, semakin tinggi kepercayaan yang diberikan website terhadap pengunjung, kemungkinan tinggi bahwa ketertarikan pengunjung dalam membeli produk yang ada didalam website.

Hal ini dapat disimpulkan bahwa pengunjung akan merasa tertarik dan berminat atas dasar kepercayaan seperti keyakinan pengunjung terhadap kejujuran pada website dan kesediaan pengunjung website dalam melakukan transaksi pada website droshipan. co.id

Ha: Kepercayaan berpengaruh positif dan signifikan terhadap minat beli pada pengunjung website

\section{KESIMPULAN}

1. Secara parsial, Kepercayaan berpengaruh positif dan signifikan terhadap minat beli pada pengunjung website 
Dropshipan.co.id berdasarkan ( $\mathrm{t}$ hitung) diperoleh koefisien regresi yang bernilai positif 0,711 dan t hitung sebesar 15.070 dengan signifikan sebesar 0,000 . Hal ini menunjukan bahwa semakin baik kepercayaan pengunjung maka akan semakin tinggi minat dalam membeli yang akan dirasakan responden pada pengunjung website dropshipan.co.id

2. Variabel kepercayaan secara varsial berpengarih positif dan signifikan terhadap minat beli pengunjung website sebesar $61,3 \%$. Hal ini dapat disimpulkan bahwa pengunjung akan merasa tertarik dan berminat atas dasar kepercayaan seperti keyakinan pengunjung terhadap kejujuran pada website dan kesediaan pengunjung website dalam melakukan transaksi pada website droshipan.co.id

\section{REFERENSI}

Ahmad makhin 2016 "pengaruh akun Instagram java foodie terhadap minat beli konsumen" fakultas ilmu social dan humaniora univerasitas islam negeri sunan kalijaga Yogyakarta

Ali Hasan. 2013. Marketing dan Kasus-Kasus Pilihan. Yogyakarta. CAPS

Amai Ishak dan Zafiri Luthfi (2011). Pengaruh Kepuasan dan Kepercayaan Pengunjung Terhadap Loyalitas: Study Tentang Peran Mediasi Switching Cost. Jurnal Siasat Bisnis No. 1 Vol 15

Arief adi satria 2017 "pengaruh harga, promosi, dan kwalitas produk terhadap minat beli konsumen pada perusahaaan A -36" jurnal manajemen dan star up bisnis

Christian. (2015). "Pengaruh bauran pemasaran terhadap kepercayaan pengunjung pasien serta dampaknya terhadap puskesmas pada pasien poli klinik umum puskesmas puter dinas kesehatan bandung" Universitas Pasundan
Dazmin Daud dan Padzil Hassan (2015).” Factors That Influence Online Purchase Intention of Online Brand" : Penang, Malaysia

Deni M. Et al, (2018) Pedoman penulisan skripsi. Sukabumi : Program studi Administrasi Bisnis Fakultas Ilmu Administrasi dan Humaniora Universitas Muhammadiyah Sukabumi.

Dikla Purbayudya Ikranegara. (2017). "Pengaruh Orientasi Belanja, Kepercayaan, dan Pengalaman Pembelian Terhadap Minat Beli Secara Online (Studi Kasus Pada Toko Online Bukalapak" universitas muhammadiyah Surakarta

Eko purnomo 2016 “ pengaruh harga, kwalitas produk dan lokasi terhadap minat beli konsumen dalam membeli beras lokal (studi kasus desa rambah utama) fakultas ekonomi universitas pasir pengaraian

Erlang prima insani 2013 "analisis pengaruh kenyamanan terhdap minat beli secara online pada pemesanan tiket kereta api melalui website resmi PT. KAI "Jurnal sain pemasaran Indonesia volume XII No 3

Fachreza dan Devilia (2017). "Pengaruh kualitas produk, harga, dan kepercayaan terhadap prooses keputusan pembelian pengunjung perusahaan konveksi inglorious industries di kota bandung" jurnal Vol.4, No.1

Ferdinand Augusty, 2002 Pengembangan Minat Beli Merek Ekstensi. Badan Penerbit Universitas Diponegoro, Semarang

Kotler, Phillip \& Keller, Kevin L. 2012 Marketing Management 14th Edition. 
United State, Pearson

Kotler, Keller 2016. Marketing Management 15th Edition United State, Pearson

Koufaris dan William (2003). "The development of initial trust in an online company by new customers" Box B11-220, New York

Miki ambarwati 2015" pengaruh citra merek terhadap minat beli" jurnal administrasi bisnis (JAB) Volume 25 No 1

Noorlaily Fitdiarini (2015). “Kepercayaan pelanggan untuk melakukan online shoping dan dampaknya terhadap minat beli ulang" Universitas Airlangga XXVI, No. 3
Sofia imari et al.,(2017) "Pengaruh orientasi belanja, kepercayaan, pengalaman pembelian sebelumnya terhadap niat pembelian pengunjung Secara Online dengan perbedaan Gender sebagai Vairabel Pemoderasi" Jurnal Perspektif Manajemen dan Perbankan Vol. 8 , No. 3

Veronika ( 2016). "Pengaruh iklan dan brand image terhadap minat beli pengunjung sebagai variable mediasi kasus calon pengunjung shampoo dove di pusat pembelanjaan: gardena departemen store dan supermarket yogyakarta"

https://www.dropshipan.co.id/aboutus 